\title{
Physician-assisted dying and palliative care: Understanding the two
}

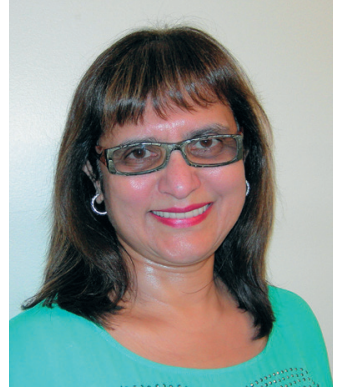

Ames Dhai

Editor

amaboo.dhai@wits.ac.za

The recent case of Stransham-Ford v. Minister of Justice and Correctional Services and Others, ${ }^{[1]}$ brought to the fore intense discussion, debate and reflection on endof-life issues. While much has been said, and rightfully so, of the patient's right to dignity and the entwining of this right with the right to autonomy as entrenched in the Constitution of South Africa ${ }^{[2]}$ with regard to physician-assisted dying, other core matters like the need for advocating for quality palliative care and the importance of taking the social context in the country into account require equal consideration too, if we are to have an evenly balanced debate.

Several terms have emerged in the discussion on euthanasia. In this article I consider the topic from the perspective of physician-assisted dying, which can be regarded as covering two different aspects: physician-assisted suicide (PAS), and euthanasia. In the former, a patient self-administers lethal drugs supplied by a doctor, and in the latter, a doctor administers lethal drugs to a patient at the patient's request. It is important to note the difference between the two with respect to the doctor's role. With PAS, while the doctor facilitates access to lethal medications, the patient plays an active role in terminating his or her own life. With euthanasia, it is the doctor that plays the active role in terminating the patient's life, with the patient being the recipient of the lethal drugs. So, in PAS, the doctor's role is facilitatory, as compared to euthanasia, where the doctor's role is active.

Palliative care, as defined by the World Health Organization, is 'an approach that improves the quality of life of patients and their families facing problems associated with life-threatening illness, through the prevention and relief of suffering, the early identification and impeccable assessment and treatment of pain and other problems, physical, psychosocial and spiritual! ${ }^{[3]}$

The intention of palliative care management is to neither hasten nor postpone death but to affirm life and uphold dying as a normal process. It does this by allowing for the provision of relief from pain and other distressing symptoms. It integrates the psychological and spiritual aspects of patient care and offers a support system to help patients live as actively as possible until death by using a team approach to address the needs of patients and their families, thereby supporting families to cope during the patients' illness and in their bereavement. It provides for bereavement counselling when required. In this way, it serves to enhance the quality of life, and positively influence the course of illness. Management with palliative care should start off early in the course of illness, together with other therapies, such as chemotherapy or radiation therapy that are used to prolong life. Moreover, palliative care management includes those investigations needed to better understand and manage distressing clinical complications. ${ }^{[3]}$

While there remains opposition to physician-assisted dying on grounds of personal morality, it is essential that the advances in all aspects of palliative care over the past few decades are taken into account during the debate. Palliative care is capable of relieving much of the suffering that once accompanied the dying process and the case for legalising physician-assisted dying should be less strong today than it was in the past. In addition, terms used by legal and other non-medical disciplines place an emphasis on 'active' and 'passive' euthanasia and scholars point out that the distinction between the two is false. Passive euthanasia is equated to withholding and withdrawing life-sustaining treatments and it is claimed that doctors are involved in acts of passive euthanasia on a regular basis with the end result being the same as active euthanasia - the death of the patient. These claims are flawed because of a lack of understanding into how healthcare practitioners manage terminally ill patients. When a decision is made to withhold or withdraw life sustaining treatments and change the trajectory of management to palliative care, this is only done when a diagnosis of medical futility is arrived at and hence death is the inevitable end result as life runs its natural course. The result of instituting palliative care is that of alleviation of pain and suffering during this period and not death. The intention is to try to make the patient as comfortable as possible in the final stages of life and that she or he lives in dignity until the very end. When death does occur, it is as part of the natural process or because of the side-effects of the treatment to alleviate pain and suffering. Certain types of medical management, e.g. some chemotherapeutic regimens also develop complications that result in death. Should oncologists whose patients demise from the side effects of chemotherapy now be told that they practise 'passive' euthanasia? These claims are irresponsible and serve to misguide the public, especially since the latter do not have an appreciation of what 'hands-on' medical management entails.

It is also essential that the process of physician-assisted dying is understood. With regard to drugs used in PAS, $9-10$ grams of a barbiturate (about 50 times the dose used clinically) is administered. Drugs used in euthanasia are similar to those used in judicial executions in the United States. These are usually a short-acting anaesthetic agent plus pancuronium. The patient is completely paralysed by the pancuronium and then dies of asphyxia. There is no available evidence as to whether the terminally ill patient, who is administrered euthanasia, regains consciousness. However, evidence does exist that the blood levels of the anaesthetic agent in $43 \%$ of executed prisoners had fallen to a point at which they may have regained a degree of consciousness by the time of death. Because of complete paralysis, official observers would not be able to detect this. ${ }^{[4]}$ 
PAS and euthanasia are not without complications. There were difficulties in administering the lethal drugs in 10\% of PAS and $5 \%$ of euthanasias in a Dutch study. Other complications included vomiting and muscle spasms during the process in $7 \%$ of PAS and $3 \%$ of euthanasias; a long time for death (up to 7 days) in 15\% of PAS and $5 \%$ of euthanasias. ${ }^{[5]}$ Similar reports have been recorded in Oregon and very long intervals from ingestion to death have been documented. Six patients who attempted PAS were reported to have re-awoken. None re-attempted PAS. ${ }^{[6]}$

Vulnerability in this context must also be considered. Not only is it linked to socioeconomic factors and other issues like elder abuse and possible coercion by family members, but also to feelings of dependency, loss of independence, inability to communicate, and psychological distress. ${ }^{[7,8]}$ Clinical depression cannot be ignored, whatever the socioeconomic status of the patient. One third of patients who were being prospectively monitored as part of a PAS research project in Oregon and who died after ingesting the lethal drugs had been suffering from clinical depression. This condition had neither been diagnosed nor referred for expert psychiatric or psychological assessment and treatment. ${ }^{[9]}$ Evidence from research confirms a strong correlation between depression and hopelessness among those requesting physician-assisted dying. ${ }^{[10]}$

The case of Stransham-Ford v. Minister of Justice and Correctional Services and Others ${ }^{[1]}$ was without doubt, a rushed decision. It did not take into consideration crucial issues like the advances in palliative care and social and cultural questions in the context of the wider public in SA. It has supported autonomy in its narrow sense and ignored the relational aspects of autonomy, which for many in the country is less individualistic and more relational to family or community values in decision-making. Respecting autonomy must respect not only the specific decision, but also the method by which the patient has chosen to make that decision. Moreover, while it is asserted that Stransham-Ford continued to suffer intractable pain despite receiving palliative care, it is alleged by reliable sources that the patient had not received palliative care prior to the application being made. ${ }^{[11]}$

There have been calls for polls from doctors and others to assist with the decision-making with regard to physician-assisted dying. Any poll should be conducted responsibly, taking into consideration all elements at hand. It is highly questionable as to whether we in SA are currently equipped with adequate information to participate in any poll on the subject. It is also questionable as to whether we are ready for legalising physician-assisted dying. Perhaps our energies ought to be channelled towards advocating for quality palliative care as a right for everyone in this country. Quality palliative care remains pretty much a 'therapeutic orphan' - both in healthcare delivery and research. We should be wary of creating a situation whereby physician-assisted dying becomes the default position by state and other agents who fail to deliver on patients' rights to access this much needed care.

\section{References}

1. Stransham-Ford v. the Minister of Justice and Correctional Services and Others. 30 April 2015, Case no. 27401/15 (NGHC) (unreported).

2. Republic of South Africa. Constitution of the Republic of South Africa. Pretoria: Government Gazette, 1996.

3. World Health Organization. WHO Definition of Palliative Care. Geneva: World Health Organization. http://www.who.int/cancer/palliative/en/ (accessed 1 November 2015).

4. Koniaris LG, Zimmers TA, Lubarsky DA, Sheldon JP. Inadequate anaesthesia in lethal injection for execution. Lancet 2005 Apr 16-22;365(9468):1412-1414.

5. Groenewoud JH, van der Heide A, Onwuteaka-Philipsen BD, et al. Clinical problems with the performance of euthanasia and physician-assisted suicide in The Netherlands. N Engl J Med 2000;342(8): 551-556. [http://dx.doi.org/10.1056/ NEJM200002243420805]

6. Jones DA. Evidence of the adverse impact in assisted suicide and euthanasia. BMJ 2015;351:H4437. http://www.bmj.com/content/351/bmj.h4437/rr-10 (accessed 1 November 2015).

7. Chochinov HM, Wilson KG, Enns M, Lander S. Depression, hopelessness, and suicidal ideation in the terminally ill. Psychosomatics 1998;39(4):366-370. [http:// dx.doi.org/10.1016/S0033-3182(98)71325-8]

8. Finlay I, George R. Legal physician-assisted suicide in Oregon and The Netherlands: Evidence concerning the impact on patients in vulnerable groups - another perspective on Oregon's data. J Med Ethics 2011;37(3):171-174. [http:// dx.doi.org/10.1136/jme.2010.037044]

9. Ganzini L, Goy ER, Dobscha SK. Prevalence of depression and anxiety in patients requesting physicians' aid in dying: Cross sectional survey. BMJ 2008; 337:a1682. [http://dx.doi.org/10.1136/bmj.a1682]

10. Smith KA, Harvath TA, Goy ER, Ganzini L. Predictors of pursuit of physicianassisted death. J Pain Symptom Manage 2015;49(3):555-561. [http://dx.doi. org/10.1016/j.jpainsymman.2014.06.010]

11. Presentation by Dr Liz Gwyther at Annual SAMA Conference. Palliative Care: Living in Fear, Dying in Despair: How Can We Help? 18 September 2015.

S Afr J BL 2015;8(2):2-3. DOI:10.7196/SAJBL.448 